\title{
Science Highlights
}

\section{Radiocarbon in Tree Rings: A Unique Treasure of Information}

\section{J. BEER}

Swiss Federal Institute for Environmental Science and Technology, 8600 Dübendorf, Switzerland; juerg.beer@eawag.ch

The radiocarbon dating method is by far the most important technique for dating the past 50,000 years. It is based on the assumption that the atmospheric ${ }^{14} \mathrm{C} /{ }^{12} \mathrm{C}$ ratio was constant at all times due to the equilibrium between production and decay of ${ }^{14} \mathrm{C}$ (halflife: 5,730 y). Living organic matter is in constant contact with the atmosphere and therefore contains the same ${ }^{14} \mathrm{C} /{ }^{12} \mathrm{C}$ ratio. At the time of death, the organic matter is decoupled from the atmosphere and the ${ }^{14} \mathrm{C} /{ }^{12} \mathrm{C}$ ratio begins to decrease according to the law of radioactive decay.

However, it is now clear that the assumption of a constant ${ }^{14} \mathrm{C} /$ ${ }^{12} \mathrm{C}$ ratio is not quite correct and that this ratio deviates by up to $20 \%$ from the value of 1950 . This corresponds to an age difference of about 1,500 years. Several leading radiocarbon laboratories made a joint effort to determine the past deviations of the atmospheric ${ }^{14} \mathrm{C} /$ ${ }^{12} \mathrm{C}$ ratio by analyzing dendrochronologically dated tree rings all the way back to 12,000 years before 1950 (Stuiver et al., 1998). This decadal $\Delta^{14} \mathrm{C}$ record is shown in

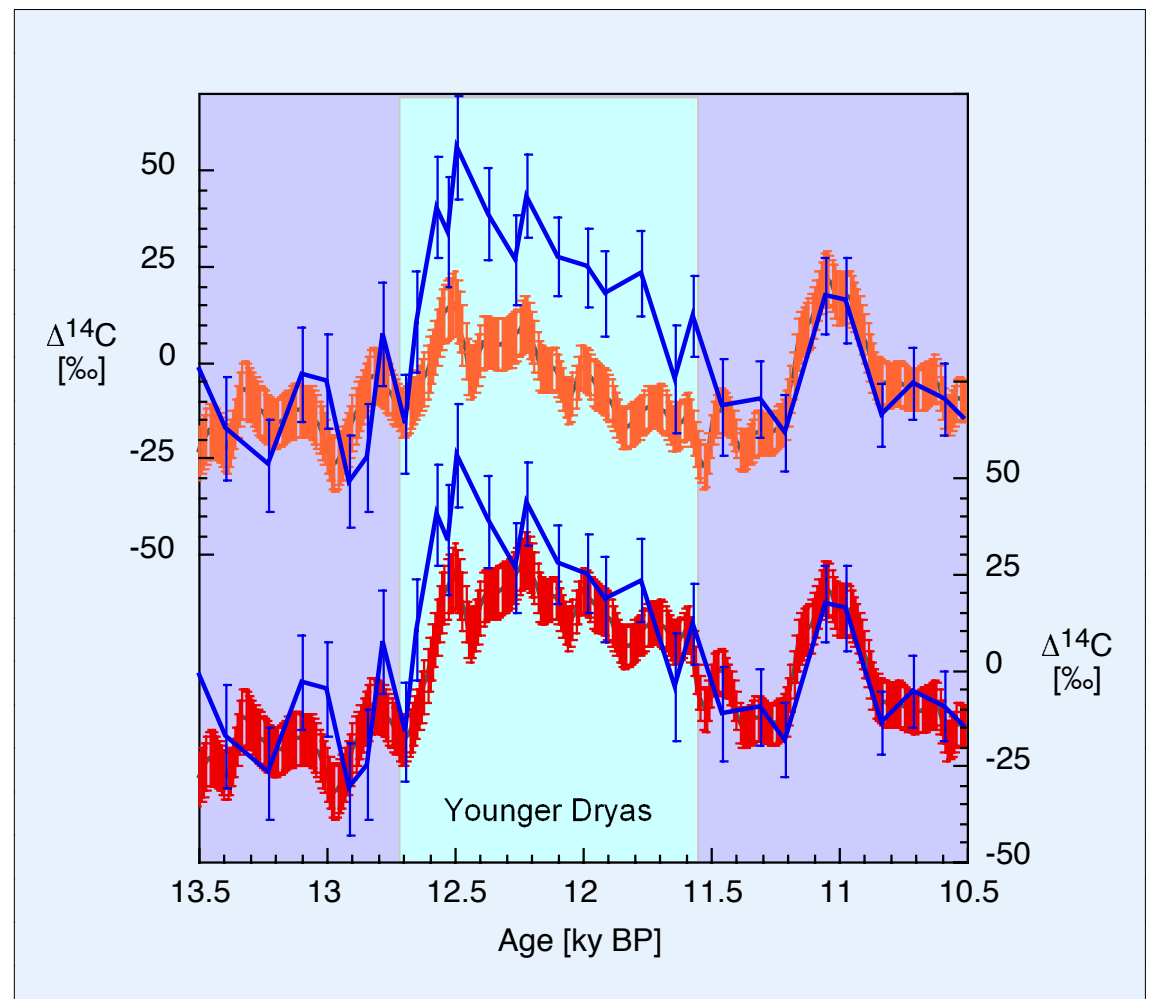

Fig. 2: Comparison of the measured $\Delta^{14} \mathrm{C}$ from tree rings with the calculated $\Delta^{14} \mathrm{C}$ derived from ${ }^{10} \mathrm{Be}$ in the GISP2 ice core (Muscheler et al., 2000). The agreement during the Younger Dryas is poor (upper set). An agreement can only be obtained by additionally reducing the global deep-water formation (lower set) figure 1 and provides the base for calibrating the radiocarbon ages. Although the observed deviations cause problems in dating, they

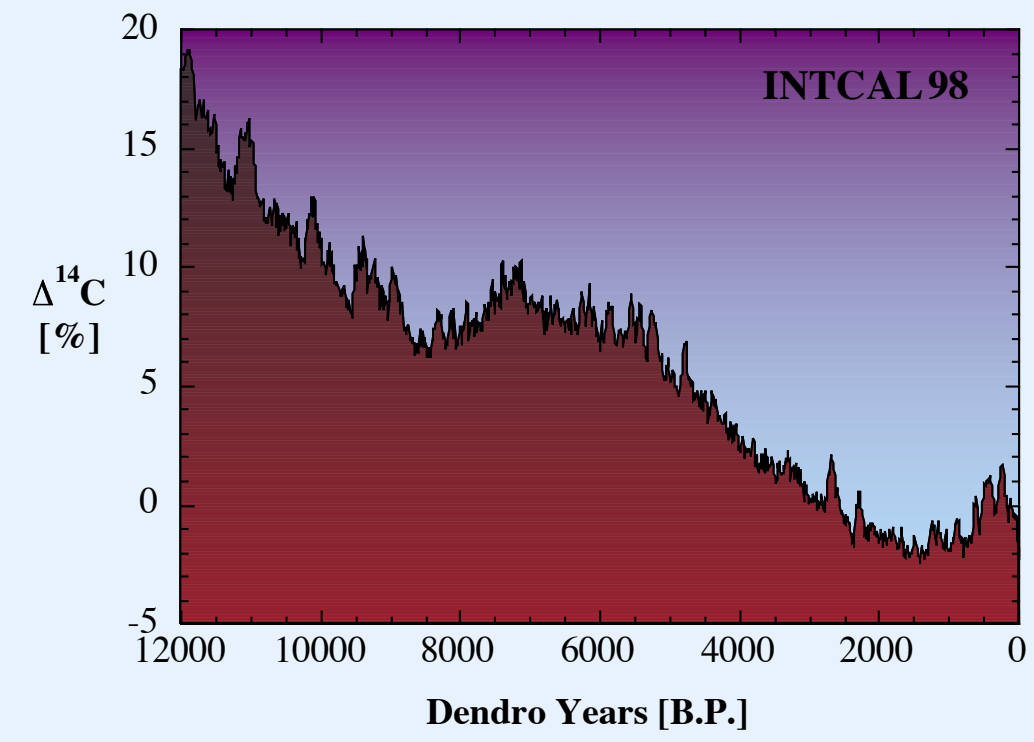

Fig. 1: Deviations of the atmospheric ${ }^{14} \mathrm{C} /{ }^{2} \mathrm{C}$ ratio from a standard value for the past 12,000 years (0 is 1950) as derived from tree rings (Stuiver et al., 1998). nevertheless provide a wealth of unique information on the history of the production of cosmogenic radionuclides and the global carbon system.

${ }^{14} \mathrm{C}$, as well as other cosmogenic radionuclides $\left({ }^{10} \mathrm{Be},{ }^{36} \mathrm{Cl}\right)$, are produced by the interaction of cosmic rays with the atoms of the atmosphere. After production, ${ }^{14} \mathrm{C}$ forms ${ }^{14} \mathrm{CO}_{2}$ and begins to exchange with the biosphere and the ocean (see cover). Interpretation of the observed $\Delta^{14} \mathrm{C}$ changes is not straightforward. Changes in $\Delta^{14} \mathrm{C}$ can be caused either by changes in the production rate (due to changes in solar activity and geomagnetic field intensity) or the carbon cycle (due to changes in size and exchange fluxes between the reservoirs). The situation is further complicated by the fact that the atmospheric ${ }^{14} \mathrm{C} /{ }^{12} \mathrm{C}$ ratio determined at a specific time not only reflects the momentary production rate and system conditions but also 'remembers' to some extent earlier changes stored in the 


\section{Science Highlights}

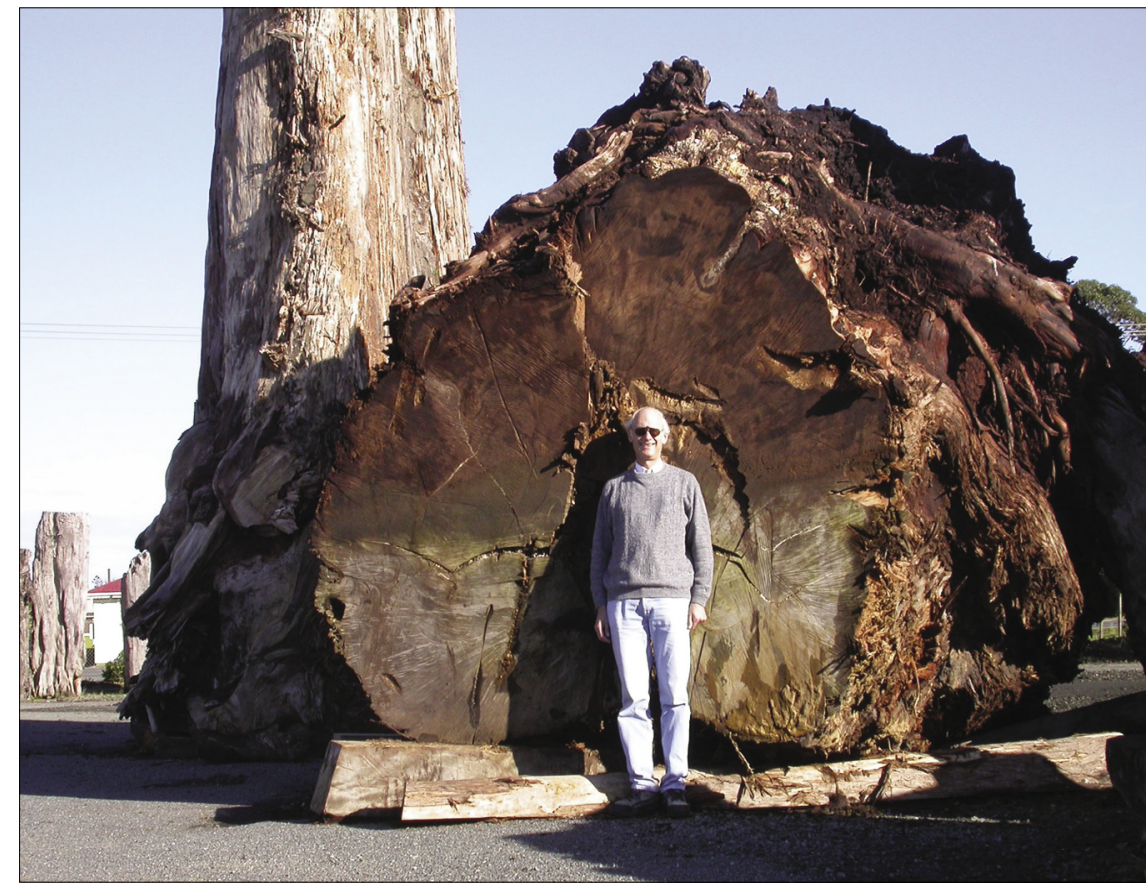

Fig. 3: Example of a fossil Kauri tree excavated in a swamp in New Zealand.

large reservoirs. Without further information, it is a priori impossible to decide whether an observed ${ }^{14} \mathrm{C}$ change is caused by solar activity, geomagnetism or ocean circulation.

One way to gain additional information is to compare the $\Delta^{14} \mathrm{C}$ record with ${ }^{10} \mathrm{Be}$ records from ice cores (see cover). ${ }^{10} \mathrm{Be}$ is produced in a very similar way to ${ }^{14} \mathrm{C}$ but its geochemical behavior is completely different. As a result of the large reservoir sizes and the relatively small exchange fluxes between them, the mean residence times of ${ }^{14} \mathrm{C}$ are quite long and range from 8 years in the atmosphere to more than 1,000 years in the deep ocean. This leads to a considerable attenuation of the amplitudes of production changes and to phase lags (Siegenthaler et al., 1980). On the other hand, the mean atmospheric residence time of ${ }^{10} \mathrm{Be}$ is only about 1 year and, therefore, ${ }^{10} \mathrm{Be}$ directly reflects production changes on decadal or longer time scales without any significant attenuation or phase lag. To compare ${ }^{14} \mathrm{C}$ with ${ }^{10} \mathrm{Be}$, the ${ }^{10} \mathrm{Be}$ record first has to be turned into $\Delta^{14} \mathrm{C}$ by means of a carbon cycle model that accounts for the different reservoirs and the exchange processes between them. In figure 2, such a comparison is made for the Younger Dryas
(13,000-11,500 BP) (Muscheler et al., 2000). The tree-ring based $\Delta^{14} \mathrm{C}$ (solid blue line) agrees well with the calculated $\Delta^{14} \mathrm{C}$ based on ${ }^{10} \mathrm{Be}$ from Greenland ice, except for the Younger Dryas period (Fig. 2, upper set). However, if, in addition, the global deep-water formation is reduced in the model by some $30 \%$, the agreement is considerably improved for this period (Fig. 2, lower set) (Muscheler et al., 2000).

This example shows the potential of this technique. The results obtained so far show that during the Holocene period (Fig. 1), $\Delta^{14} \mathrm{C}$ can be explained to a very large extent by a combination of solar and geomagnetic modulation. The short-term peaks are mainly due to periods of reduced solar activity (Maunder Minimum type events) while the long-term trend is mainly the result of changes in the geomagnetic dipole moment. There is no evidence of significant ${ }^{14} \mathrm{C}$ changes caused by the global ocean circulation or other system effects during the past 12,000 years.

However, the last glacial, which was characterized by large and abrupt climate changes, shows clear indications of considerable changes in the carbon cycle. To investigate these changes, an extension of the high-precision tree-ring calibration curve is indispensable. There are already a considerable number of $\Delta^{14} \mathrm{C}$ reconstructions in various archives (sea and lake sediments, stalagmites). However, a high-precision, high-resolution atmospheric ${ }^{14} \mathrm{C} /{ }^{12} \mathrm{C}$ record covering the period $12,000-50,000 \mathrm{BP}$ is still missing.

Existing chronologies based, for example, on German oak trees, cannot be extended into the glacial period because there were no oak trees in Germany at the time. An excellent opportunity to cover the glacial period is offered by the Kauri trees in New Zealand (Buckley et al., 2000). Kauri trees have been growing in New Zealand for at least the past 50,000 years and are quite easily found in swampy areas (Fig. 3).

An extension of the tree-ring calibration curve to 50,000 years is not only fundamental to the radiocarbon dating technique, in combination with other radionuclides it also provides unique information on solar variability, paleomagnetism, the carbon cycle in general, and the ocean circulation in particular.

\section{References}

Stuiver, M., et al., 1998: INTCAL98 Radiocarbon age calibration, 24,000-0 cal BP. Radiocarbon, 40(3): 1041-1083.

Siegenthaler, U., Heimann, M. and Oeschger, $H_{\text {., }}$ 1980: 14C Variations Caused by Changes in the Global Carbon Cycle. Radiocarbon, 22(2): 177-191.

Muscheler, R., et al., 2000: Changes in deep-water formation during the Younger Dryas cold period inferred from a comparison of $10 \mathrm{Be}$ and $14 \mathrm{C}$ records. Nature, 408: 567-570.

Buckley, B., et al., 2000: Dendroclimatic interpretation of tree-rings in Agathis australis (kauri). Journal of the Royal Society of New Zealand, 30(3): 263-275.

\section{6 \\ Contribute: \\ Is this your field of expertise? \\ Would you like to help start a related PAGES Initiative? If so, please contact Christoph Kull at the IPO (kull@pages.unibe.ch).}

